\title{
Anaplastic Lymphoma Post-Transplant Lymphoproliferative Disorder
}

National Cancer Institute

\section{Source}

National Cancer Institute. Anaplastic Lymphoma Post-Transplant Lymphoproliferative

Disorder. NCI Thesaurus. Code C7247.

An anaplastic lymphoma that arises in a patient with a history of org an transplantation. 